\title{
INVESTIGACIÓN Y TRANSMISIÓN DE LA FILOSOFÍA SĀṂKHYA
}

\section{RESEARCH \\ AND TRANSMISSION OF SĀṂKHYA PHILOSOPHY}

\author{
JUAN ARNAU* \\ Universidad Europea de Valencia
}

RESUMEN: El artículo repasa las diferentes fases en la investigación y transmisión de la filosofía sāṃkhya. Desde sus primeras apariciones en la literatura antigua, que se remontan al periodo postvédico, hasta su sistematización en el periodo clásico por parte de Î́varakṛ̦̣na en la Sāṃkhyakārikā (finales del siglo IV), prestando especial atención al comentario sánscrito medieval de Vācaspati Miśra titulado Tattvakaumudī (siglo X). Asimismo, se analizan las diferentes interpretaciones de esta tradición de pensamiento realizadas en India y Europa en el periodo 1896-1970 por Jhā, Dasgupta, Frauwallner y Larson.

Palabras clave: Sāṃkhya; cosmología; Säṃkhyakārikä; Tattvakaumudī; transmisión del conocimiento.

AвSTRACT: The present paper focuses on the reconstruction of the transfer of knowledge of sāṃkhya philosophy, from its first manifestation in the post-Vedic period of ancient literature to its systematization in the Sāmkhyakārikā of İ́varakrṣna (late 4th century). Special attention is devoted to the medieval Sanskrit commentary of Vàcaspati Miśra titled Tattvakaumudī (10th century). The interpretations of this tradition of thought in India and Europe during the period 1896-1970 by Jhā, Dasgupta, Frauwallner, and Larson are also analyzed.

KeYwords: Sāṃkhya; cosmology Sämkhyakärikā; Tattvakaumudī; transmission of knowledge.

* Universidad Europea de Valencia, c/ General Elio n. ${ }^{\circ}$ 2, 8 y 10. Valencia 46010. email: arnaujuan@gmail.com 


\section{Introducción}

En el sāṃkhya encontramos ciertos ecos de la cosmovisión védica. Frente al tiempo lineal característico de las tradiciones occidentales, la Antigüedad india concibió el cosmos como un proceso cíclico de acontecimientos recurrentes en periodos de larga duración. Estas concepciones estuvieron asociadas a los ciclos astronómicos y biológicos cuyas periodicidades regulaban las diferentes actividades sociales y fijaban el calendario ritual. La época védica se ocuparía de inventariar las diferentes unidades de tiempo mediante la observación de las trayectorias del Sol y de la Luna. Los movimientos de los cuerpos celestes revelaban el carácter cíclico del tiempo y por tanto repetible, siendo el tiempo lineal tan sólo un segmento dentro de cada ciclo, afianzando con ello la idea de que el pasado podía servir de modelo al presente.

La época védica fue además consolidando la idea del tiempo como una serie o conjunto de percepciones, tiempo interiorizado, que encontraba su fundamento en el devenir consciente de cada individuo. Dicha vivencia interna del tiempo adquiriría después un importante papel, tanto en las upaniṣad como en el sāṃkhya. Lo temporal era visto, desde esta perspectiva, como una presencia no necesariamente subordinada a una eternidad jerárquicamente superior a ella o que fuera emanación de algo inmóvil o atemporal.

De manera general, podría decirse que desde la Antigüedad las ideas acerca del tiempo se concibieron al menos de tres modos diferentes (o mediante una combinación de éstos): como una realidad en sí misma, independiente de las cosas; como una propiedad de las cosas (especialmente de los seres conscientes); y como un orden. Realidad absoluta, propiedad o relación. Tres caracterizaciones que también podrían aplicarse al espacio. La época moderna daría representantes de estas tres «escuelas». Newton concebía en sus Principia que «el tiempo absoluto, verdadero y matemático, por sí mismo y por su propia naturaleza, fluye uniformemente sin relación con nada externo». Mientras las cosas cambian, el tiempo no cambia. Los cambios en las cosas son cambios con relación a un tiempo uniforme, perfectamente homogéneo, que es indiferente de aquello que contiene y que se mueve en una sola dirección. Frente a esta postura, Leibniz defendería una concepción relacional del tiempo, siendo éste «el orden de existencia de las cosas que no son simultáneas», no siendo posible afirmar que el tiempo sea algo distinto de aquello que existe en él. Los instantes, considerados sin las cosas, no son nada en absoluto. Kant se fraguaría una idea del tiempo que se haría un sitio entre ambas posiciones. Para el filósofo de Königsberg el tiempo no era un concepto empírico derivado de la experiencia, sino un a priori que subyace a toda actividad cognitiva. 
El pensamiento indio insistió en una concepción del tiempo como acto cognitivo. La cosmología sāṃkhya tiende a considerar la conciencia como el factor que crea el receptáculo donde habitan los seres y no a la inversa, como se entiende en la concepción moderna del espacio. Esta idea será desarrollada fundamentalmente por esta escuela, que hará del principio intelectivo (buddhi) el fundamento del espacio y del tiempo. La cosmovisión cuyo desarrollo histórico presentamos pone el énfasis en la continuidad frente a la escatología. La idea de un comienzo y final de los tiempos es extraña al pensamiento indio, eludiendo así la cuestión de si el mundo ha sido creado o existe por sí mismo. Las diferentes fases de la literatura sāṃkhya establecerán las concepciones del espacio y del tiempo que predominarán en la época clásica, ofreciendo una concepción de la vida consciente y del cosmos como un proceso de continuo crecimiento y disminución, de muerte y regeneración.

Lo sensible, según se sabe, permite dos tipos de ensimismamiento, respecto al objeto percibido o respecto al hecho mismo de percibir. En el primer caso somos atraídos por lo que nos rodea y, si queremos profundizar en esa dirección, debemos olvidarnos hasta cierto punto de nosotros mismos. En el segundo, el mundo exterior sólo colorea y da forma al reconocimiento mismo de la percepción, adquiriendo un papel secundario, auxiliar, a una actividad sensible reflexiva. Puede decirse que toda cosmología se recrea en una de estas dos tendencias y, aunque en el pensamiento europeo no faltan buenos ejemplos del ensimismamiento en la percepción (Berkeley, Hume), es ésta quizá la actitud predominante en el pensamiento indio, que también ofrecerá ejemplos de la primera, como en la escuela nyāya. Las sociedades tecnológicas modernas se han caracterizado por el desarrollo de los mecanismos de percepción externa. Vemos el rastro que las partículas elementales dejan en las cámaras de burbujas, observamos como el fotón atraviesa dos rendijas al mismo tiempo, los radiotelescopios nos permiten escuchar la radicación cósmica de fondo. Y, civilizacionalmente, podría decirse que estos avances no son independientes de un descuido de los mecanismos de percepción interna.

\section{Cosmología sāṃkhya}

La primera de las grandes cosmologías del periodo clásico se debe al sāṃkhya, uno de los sistemas especulativos más antiguos de la tradición brahmánica. Es posible que el sāṃkhya no siempre fuera ortodoxo. Uno de los primeros historiadores de esta escuela, Richard Garbe, sugirió en los años veinte del pasado siglo que, en sus orígenes, el sāṃkhya bien pudo ser un movimiento de oposición a los 
excesos ceremoniales y rituales del brahmanismo ${ }^{1}$. Sea como fuere, con el tiempo se convertiría en una de las escuelas clásicas del pensamiento indio. Aunque estas escuelas se encuentran ya, en el periodo clásico, marcadas por la escritura, en sus orígenes el sāṃkhya surgió de tradiciones orales. Podemos encontrar referencias a esta escuela desde las primeras upanișad (Chändogya 800-600 a. EC), hasta las más tardías (Katha, Śvetāsvatara 400-200 a. EC). También en tratados de ciencia política como el Arthaśästra (Kauțilya, 300 a. EC), en las grandes épicas (en el Mokșadharma y la Bhagavadgìtā del Mahābhārata, 200 a. EC-200), en algunos dharmaśāstra como Manusmrti (200 a. EC-200), en biografías sánscritas de Gautama Buda como el Buddhacarita (Aśvagoșa, ca.100), en compendios de medicina como el Carakasambitā (Caraka, ca. 100-200) y el Suśrutasamhitā (ca. 200-300), y en la literatura enciclopédica de los purāna (Mãrkandeya, Vãyu y otros, del año 300 en adelante). La abundancia de alusiones, referencias o fragmentos del sāṃkhya en todas estas obras permite inferir que gozaba de un gran prestigio e influencia en la antigüedad.

Sin embargo, el documento más antiguo del que disponemos es relativamente tardío. La Sämkhyakārikā (SK) de İśvarakṛsna, un compendio sistemático en setenta estrofas, data de finales del siglo IV. Erich Frauwallner (1973) y, más recientemente, Gerald Larson (1987), han dedicado dos estudios muy completos a la reconstrucción de los itinerarios de esta tradición de pensamiento. El presente artículo se propone analizar la cosmología sāṃkhya desde una perspectiva histórica, a partir de los comentarios a la obra de İśvarakṛșna, que datan de la época clásica y medieval, cuando el sistema ya se encontraba completamente desarrollado. Uno de los primeros trabajos de reconstrucción de la filosofía sāṃkhya se debe a Garbe (1917), que analiza el sāṃkhya desde la perspectiva de la antigua filosofía natural y el sistema se considera creación personal de Kapila o Pañcaśikha. Por otro lado Dasgupta realiza su reconstrucción desde el lado opuesto, a partir de los comentarios medievales, sobre todo el Śämkhyapravacanabhāṣya de Vijñāna Bikṣu (s. XVI), pero también el Śämkhyakārikābhāsya de Gaudapāda (ca s. vi) y el Tattvakaumudī (TK) de Vācaspati Miśra (s. IX-X).

Frauwallner $(1973,222-27)$ fue de los primeros en insistir en el carácter germinal de la contribución sāṃkhya al pensamiento indio. Sólo el nyāya-vaiśeșika y el budismo temprano son comparables en antigüedad. Mientras que otras tradiciones de pensamiento pudieron surgir de ámbitos rituales y dialécticos, es posible que el

${ }^{1}$ Garbe, Richard. Sāṃkhya. Encyclopaedia of Religions and Ethics, James Hastings (ed.); 1927: vol. 11: 189-92. 
sāṃkhya lo hiciera de tradiciones matemáticas, astronómicas o médicas, lo que explicaría su inclinación por la cosmología racional. El sāṃkhya, por otro lado, desarrollará toda una teoría del cuerpo humano, que se mantendrá ligada a las tradiciones del yoga así como a las diferentes corrientes médicas y terapéuticas del ayurveda.

\section{Escuela de la enumeración}

El prestigio del número, como entidad abstracta o como vida propia, en la Grecia clásica asociado a los pitagóricos, tuvo en la antigua India sus representantes en el sāṃkhya, que se servía de un amplio conjunto de tablas numéricas donde se encapsulaban los diferentes elementos de lo real. Esta escuela de la «enumeración» (significado literal del término «sāṃkhya») elaboraría una compleja cosmología cuya influencia se extendería a otras disciplinas como la medicina, la política o las leyes, así como a la literatura épica y devocional.

La tendencia a agrupar su terminología en parejas, tríos, quintetos o septetos, no es nueva. Encontramos estrategias similares en textos médicos como el Carakasam hitāo o budistas como el Añguttaranikāya. Ello podría sugerir vínculos con el pitagorismo, aunque la evidencia de que disponemos no permite aclarar la cuestión (Larson y Bhattacharya, 1987, 86-90). También es posible relacionar esta metodología con la música, la astronomía y la recitación sacra, donde los números primos desempeńarían un importante papel. Jean Filliozat (1949) ha investigado la transferencia de conocimiento entre India y Grecia y los más que probables contactos entre ambas civilizaciones en los primeros siglos antes de nuestra era, seguramente a través de Persia. Richard Garbe da por hecho que las relaciones entre India y Alejandría se consolidaron en los primeros siglos de la era común, con el imperio kuśana y el apogeo del arte grecobúdico de Gandhāra. Para el estudioso alemán ello explicaría la influencia del sāṃkhya en los sistemas gnósticos y neoplatónicos². El tema es fascinante y el debate entre paralelismos e influencias ha durado algo más de

2 Garbe 1927; vol. 11, 191: «En verdad no es accidental que el neoplatónico Plotino no sólo compare el alma con la luz, como hace el sāṃkhya, sino que también haga uso de otra comparación, la del espejo en el cual aparecen las imágenes de los objetos, tal y como ocurre en la literatura sāṃkhya. Este hecho constituye uno de los argumentos en favor de una influencia directa del sāṃkhya en las doctrinas neoplatónicas.» Richard Garbe (1857-1927), profesor de la Universidad de Tubinga, fue uno de los primeros orientalistas alemanes dedicados al sāṃkhya, en una época en la que el tema de las relaciones entre la antigüedad griega e india se encontraba en su máximo apogeo. Garbe residió más de un año en Benarés en 1885, estancia financiada por el gobierno prusiano y la Academia de Ciencias de Berlín, estudió sánscrito y filosofía hindú, experiencias que consignó en un diario que publicaría en 1889. 
un siglo. Hoy día, la mayoría de los investigadores prefiere dejar la cuestión abierta. Si hubo préstamos o sincronicidad arquetípica es algo que no podemos saber.

\section{Componentes del mundo}

Pasemos ahora analizar algunos de los contenidos de esta cosmología. La primera taxonomía que cabe mencionar es la de los veinticinco principios o elementos constitutivos de lo real ${ }^{3}$. Estos principios (tattva) no gozan todos de un mismo estatus y no aparecen simultáneamente en el proceso evolutivo del cosmos, sino que se ordenan jerárquicamente del siguiente modo.

\section{Tabla I. Los componentes del mundo (25 tattva)}

\begin{tabular}{|c|c|c|}
\hline \multicolumn{3}{|c|}{$\begin{array}{c}\text { (1) Conciencia sin contenido (puruṣa) } \cap \text { (2) Materia primordial (prakṭti) } \\
\downarrow \\
\text { (3) Principio intelectivo (buddhi, mahāt) } \\
\downarrow \\
\text { (4) Sentido de la identidad o sentido del yo (ahamkāra) }\end{array}$} \\
\hline \multicolumn{2}{|c|}{ (5) Mente (manas) } & \multirow{2}{*}{$\begin{array}{l}\text { Elementos sutiles } \\
\text { (tanmātra) }\end{array}$} \\
\hline $\begin{array}{l}\text { Facultades sensoriales } \\
\text { (buddhindriya) }\end{array}$ & $\begin{array}{l}\text { Capacidades } \\
\text { (karmendriya) }\end{array}$ & \\
\hline (6) oír (śrotra) & (11) hablar (vāc) & (16) sonido (śabda) \\
\hline (7) tocar (tvac) & (12) asir (pāṇ̂̄) & (17) contacto (sparśa) \\
\hline (8) ver (cakșus) & (13) mover (pāda) & (18) forma o imagen (rūpa) \\
\hline (9) gustar (rasana) & (14) excretar (pāyu) & (19) gusto (rasa) \\
\hline \multirow[t]{8}{*}{ (10) oler (ghrāna) } & (15) procrear (upastha) & (20) olor (gandha) \\
\hline & & $\downarrow$ \\
\hline & & $\begin{array}{l}\text { Elementos físicos } \\
\text { (mahābhūta) }\end{array}$ \\
\hline & & (21) espacio (ākāśa) \\
\hline & & (22) viento (vāyu) \\
\hline & & 23) fuego (tejas) \\
\hline & & (24) agua (ap) \\
\hline & & (25) tierra (pṭthivî) \\
\hline
\end{tabular}

3 Para la Sām khyakārikā sigo la edición del texto sánscrito en Larson, Appendix B, p. 255-277. Se trata de una edición basada fundamentalmente en la de Colebrooke-Wilson, donde se incluye el comentario de Gaudapāda, y en la de Suryanarayana Sastri, que incorpora pequeñas variaciones sobre la anterior. Como advierte el propio Larson, no se trata de una edición crítica al uso: «It is simply a version of the text presented for the convenience of the reader». 
El comentario más esclarecedor de las Säṃhyyakārikā aparecerá cinco siglos más tarde. Su autor, Vācaspati Miśra (900-980), un brahmán que vivió cerca de la frontera de Nepal y del que apenas se sabe nada, salvo que compuso diversos $\mathrm{y}$ valiosos comentarios sobre las diferentes escuelas de pensamiento ortodoxas, entre ellas el sāṃkhya. El Tattvakaumudī (Esclarecimiento de los principios, Jha 1896) ${ }^{4}$ clasifica los 25 principios según sean germinantes o germinados ${ }^{5}$. Esta cuádruple división se establece en términos de su eficacia creativa: (1) meramente creativos, (2) creativos y creados, (3) meramente creados, (4) ni creados ni creativos. El principio intelectivo (buddhi [3]), pertenece a la segunda categoría. Es creativo porque a partir de él se desarrolla el sentido de la identidad (ahaṃkāra) y es creado porque en sí mismo es una evolución de la materia primordial (prakrti). Esta categoría la comparte también el sentido del yo (ahamkāra, [4]) y los cinco elementos sutiles (tanmātra [16-20]), que son los creadores de los elementos físicos. Los meramente creados son la mente (manas) [5]), los cinco principios cognitivos (buddhindriya [6-10]), las cinco facultades de acción (karmendriya [11-15]) y los cinco elementos físicos (mahābhüta [21-25]). El único principio exclusivamente creativo es la material primordial, prakrti, que ha existido siempre, ya sea en su estado manifiesto (vyakta) o en su estado latente (avyakta).

Los dos primeros principios, purușa y prakrtit, son independientes uno del otro. Uno representa una conciencia inmutable, plural y sin contenido, el otro la materia original de la que está hecho todo lo dado (ya sea manifiesto o latente). Son los únicos principios cuya naturaleza es autónoma, cuya existencia no depende de la existencia de otras cosas, y por tanto no son función de las condiciones espaciales y temporales del cosmos, sino más bien al contrario: el espacio y el tiempo pueden considerarse como una consecuencia de su copresencia. La Sämkhyakārikà los definen como principios fuera del espacio y del tiempo, simples, carentes de partes, estables, no generados o producidos por alguna otra cosa, no sujetos al surgimiento o la desaparición, no apoyados en nada e independientes ${ }^{6}$. Ni siquiera el despliegue y repliegue periódico del cosmos los afecta, es más, dicho despliegue y repliegue tiene su razón de ser precisamente en dichos principios. La relación entre ambos es de copresencia o coexistencia ${ }^{7}$.

\footnotetext{
${ }^{4}$ Kaumudì significa "claro de luna», haciendo referencia a que bajo su luz crecen los lotos blancos (kumuda), pero en un contexto filosófico se refiere a un ejercicio de aclaración o esclarecimiento, en este caso de los 25 principios (tattva) del sāṃkhya.

5 JHĀ,Gangānāta. The Samkhya-Tattva-Kaumudi: Vacaspati Misra's Commentary on the Samkhya-karika. Delhi: Chaukhamba Sanskrit Pratishthan; 2004. (1. a edición, Bombay 1896).

6 SK 10. Larson, n. 9, p. 258.

7 SK 19. Larson, n. 9, 261.
} 
El puruşa es esencialmente inactivo mientras que la materia primordial es fundamentalmente generativa. Ella es la responsable de todo el conjunto de principios que configuran la jerarquía del universo natural, generación que se activa por la presencia de la conciencia, que decanta el proceso de transformación del mundo (parimāna) sin implicarse en él.

\section{Causalidad en la cosmología sāṃkhya}

El fundamento del mundo natural es la llamada materia primordial (prakrti o mülaprakrti). Se define como increada (ha existido siempre, carece de origen o nacimiento: avikrti) y creativa (genera el mundo). Se trata de una noción que amplía la idea común que se tiene de la materia, pues abarca también a lo inmanifiesto, al ámbito que guarda, en estado latente (en equilibrio tenso de los guna), todo lo que el mundo será ${ }^{8}$. La materia primordial constituye, en sí misma, la fuerza generativa que produce la diversidad del cosmos. Se encuentra constituida por tres sustancias (triguna o traigunya) que guían sus continuas transformaciones. En el orden global de la naturaleza, los gun a determinan la actividad de la prakrti y los diversos estados que experimenta en su evolución: satisfacción, frustración o confusión, abarcando tanto estados subjetivos como objetivos, ya sean en forma manifiesta (vyakta) o potencial (avyakta).

Para entender la cosmología sāṃkhya es necesario entender previamente su idea de la causalidad. Los textos definen la causa como un ímpetu que lleva en sí, de forma latente, el efecto (satkāryavāda). O, por decirlo de otro modo, la preexistencia del efecto en la causa ${ }^{10}$. De modo que causa y efecto comparten una misma naturaleza ${ }^{11} \mathrm{y}$ los efectos subsisten in aeternus, oscilando cíclicamente entre su forma potencial (avyakta) y su forma manifiesta (vyakta), que es cuando, convencionalmente, adquieren la calidad de «efecto». ¿Qué justifica dicha aserción? En primer lugar el hecho de que una no entidad no puede, en ningún caso, transformarse en una entidad. La existencia no puede derivar de la inexistencia, como en la escolástica, ex nibilo nibil fit: «de la nada, nada adviene». Pero no sólo eso: un ente tampoco puede desaparecer en la nada, sólo transformarse. Debe

\footnotetext{
8 Compárese con las nociones cosmológicas modernas de antimateria y de materia oscura.

9 Conviene apuntar que los guna no se cuentan entre los 25 tattva que constituyen el mundo natural, sino que son, por así decirlo, su fuente de alimentación, el axioma o fundamento que permite entender el proceso continuo de transformación que es el mundo.

10 SK 8. (Larson, 1987, 258).

11 SK 9. (Larson, 1987, 258).
} 
existir entonces algún tipo de relación que ate el afecto a la causa y lo que no tiene entidad carece de relaciones, de lo contrario el efecto podría ser resultado de una causa cualquiera, lo que supondría negar la causalidad misma, convertida en mero azar. Todo ello contradeciría la experiencia empírica y científica: la regularidad que observamos en la naturaleza. No se mantiene que el efecto sea idéntico a la causa, simplemente se niega que sean esencialmente diferentes. Siendo el efecto una causa desarrollada o desplegada, se infiere que lo manifiesto deberá ser consecuencia de lo inmanifiesto. La idea de un estado potencial o latente (avyakta) del cosmos sustituye aquí al concepto de creación ex-nibilo.

Todo lo manifiesto, desde el principio intelectivo (buddhi) hacia abajo, deberá ser entonces resultado de un principio original, latente, (pradhāna, avyakta, prakrti). Y para definir dicho estado será necesario recurrir a lo manifiesto, a los efectos de prakrti. La propia experiencia reflexiva y la observación empírica nos lleva a considerar estos efectos como fugaces, limitados, en continua transformación, dependientes y diversos. La materia no manifiesta carece de cualidades sensibles que permitan percibirla, pero ello es debido a su estado latente o potencial, no a su inexistencia. Se conoce mediante la inferencia de la causa a partir de sus efectos (el mundo en transformación). En este sentido, el juego entre lo intemporal y lo efímero, entre lo estable e inestable, se explica en términos de lo potencial y lo manifiesto. En el universo del sāṃkhya no hay verdaderas novedades, ni tampoco verdaderas desapariciones, sino simples despliegues de las causas en los efectos o repliegues de los efectos en las causas. Nada nuevo se produce en el mundo, todo se encuentra contenido en la materia primordial cuando todavía no se ha manifestado y toda la diversidad del mundo regresará a ella tras su repliegue.

Si lo fenoménico y transitorio se define en oposición a lo estable y eterno, los productos de la materia primordial, lo manifiesto (vyakta), los veintitrés principios que constituyen el mundo tal y como se da a conocer, serán todos ellos causados, finitos, transitorios, maleables, diversos, dependientes, determinados, compuestos y contingentes. Mientras que lo no manifestado (avyakta) será lo opuesto a esta caracterización y, al mismo tiempo, su fundamento y causa ${ }^{12}$. Lo no manifestado es causa de sí mismo, de él emana el mundo y en él se reabsorbe, siguiendo ciclos recurrentes de despliegue y repliegue.

12 SK 10. (Larson, 1987, 258) 


\section{Principios naturales}

Ya hemos mencionado los tres hilos que trenzan la cuerda del universo (los tres guṇ), el Tattvakaumudī lo examina en detalle ${ }^{13}$. La palabra sánscrita guṇa significa literalmente cabello, hilo o filamento, haciendo referencia a las tres hebras trenzadas que componen una cuerda. El término puede significar también cualidad, genio, inclinación, condición o temperamento. El sistema sāṃkhya postula tres constituyentes de la materia primordial (prakrti), tres temperamentos o humores (triguna): uno contemplativo (pura serenidad), otro activo (pura inquietud) y un último pasivo (pura inercia), asociados al placer, el dolor y la indiferencia respectivamente. Todas las cosas creadas resultan de algún tipo de mezcla de estas notas distintivas, desde el mineral al planeta, desde la más insignificante brizna de yerba hasta el más engolado de los dioses. El paralelismo con Hipócrates es evidente. El griego distinguía a los individuos de acuerdo a la predominancia de uno de los cuatro humores, que daban lugar a temperamentos sanguíneos, flemáticos o melancólicos. Los cosmólogos del sāṃkhya atribuirían su taxonomía tripartita a todos los entes manifiestos e inmanifiestos, ya fueran conscientes o inconscientes, e incluso a las categorías del espacio y el tiempo. Aunque nuestro lenguaje hable del siglo de las luces o de épocas oscuras, y el espacio se curve en presencia de agujeros negros o luminosas estrellas; cuesta imaginar en el espacio o el tiempo una naturaleza temperamental. Habitualmente pensamos que los humores ocurren en el espacio y en el tiempo y no a la inversa. Sin embargo, esta fue una idea recurrente en India a la que no se le ha prestado suficiente atención, quizá por nuestra incapacidad de hacernos cargo de ella.

El primero de ellos, el guna sattva, se asocia con lo ligero, lo expansivo, lo blanco y lo transparente. El segundo, rajas, con lo activo, lo rojo y lo móvil. El tercero, tamas, con lo pesado, lo negro y lo sólido. Los productos finitos y fugaces del mundo comparten, con el fundamento eterno e infinito que los produce, estas tres sustancias, que constituyen tanto lo manifiesto (vyakta), como lo inmanifiesto $(\text { aryakta o pradhāna })^{14}$. Salvo que en este último caso los tres guṇa se encuentran en estado de equilibrio. Dasgupta describe la prakrti, en su estado latente (avyakta), no como un equilibrio sereno, sino tenso. Su intensidad inherente será capaz de crear, cuando sea desestabilizada por el puruṣa, toda la diversidad de lo natural. En dicho estado, como en el equilibrio entre la fuerza concéntrica de la gravedad y la fuerza excéntrica del horno nuclear en el interior de las estrellas, la actividad expansiva

13 SK 11-20. (Larson, 1987, 259-266). TK 89-137. (Jhā, 1896, 37-60).

${ }_{14} S K 11$. (Larson, 1987, 259) 
(rajas) se encuentra compensada por la gravedad de lo inerte (tamas $)^{15}$. Cuando dicho equilibrio es perturbado, mediante la intervención (mera presencia) de la conciencia, se inicia el proceso de diversificación de la materia original, según la secuencia esbozada en la Tabla I. El mundo evoluciona mediante transformaciones debidas a la interacción de los guna, que son los que constituyen el engranaje del mundo y producen la diversidad de fenómenos y seres. Pero, al mismo tiempo, también son ellos los que permiten a dichos seres inferir lo no manifiesto de lo manifiesto. Dado que el principio fundacional del universo se compone de estas tres sustancias (sattva, rajas y tamas), puede decirse que ellas constituyen lo único real. Los guna subsisten a todas las transformaciones, ni se crean ni se destruyen, y de ahí que algunos comentaristas las hayan considerado sustancias ${ }^{16}$.

\section{Inteligencia y Yo}

En la cosmología sāṃkhya toda realidad, todo ente, es una posición. La primera emanación de la materia primordial (mülaprakrti) es un principio de inteligibilidad denominado técnicamente buddhi y que es la forma más sofisticada de la materia, su forma emergente, en la que predomina los aspectos luminosos del guna sattva (del que hablaremos más adelante). Se trata de una inteligencia que se encuentra todavía lejos de ser la facultad de un sujeto o la capacidad de un organismo de adaptarse a situaciones nuevas. No hay todavía, es este estadio de la evolución cósmica, entidades o individuos. Pero dicha inteligencia no carece de aspectos gnoseológicos y para desarrollarlos se fabrica un yo, un sentido de la identidad (ahaṃkāra). Observemos la originalidad de la cosmovisión sāṃkhya: la inteligencia no es aquí una potencia del yo, sino más bien a la inversa. Y esa inteligencia no es una entidad metafísica de ordenación del cosmos, sino una consecuencia de la evolución de la materia. La evolución natural conduce a un principio de individuación donde la identidad o el sentido del yo es resultado (o tendencia inevitable) del desdoblamiento de la inteligibilidad, que necesita de entidades sobre las que predicar y que no sean ellas mismas atributos ${ }^{17}$.

15 (Dasgupta, 1922, 247)

16 (Pujol y Domínguez, 2009, 81).

17 La época moderna ha considerado de manera diversa la naturaleza de lo individual. Algunos filósofos han tratado la cuestión bajo el aspecto de la relación entre los entes singulares y la totalidad del universo, preguntándose a tal efecto si los entes singulares son simples modos de una sustancia única (el caso de Spinoza), frente a aquellos que han subrayado la singularidad irreductible de lo individual (Leibniz). 
No hay, en este estadio de la serie de transformaciones (parinàma), una dependencia de la inteligencia con el sentir, ya que los estímulos del sentir presuponen un sujeto que les sirva de sede, y ese sujeto no se ha formado todavía. Lo sensible se constituirá posteriormente, como resultado de la combinación del sentido del yo (ahamkāra) y de la mente (manas), que darán lugar a las diez capacidades (motoras, sensibles y mentales) y a los cinco elementos sutiles (sonido, tacto, forma, gusto y olfato). Será a partir de éstos últimos que se creen los cinco grandes elementos. No se trata pues de que el mundo se haga cognoscible gracias a buddhi. El mundo, con su diversidad y pluralidad, no existe todavía y es esa inteligibilidad la que lo estructura y le da forma.

Vācaspati Miśra define este principio de ordenación (buddhi) como adhyavasāya, término que se puede traducir por «determinación». Ello ha llevado a algunos estudiosos, como Ganganatha Jha, a asociarlo con la noción de voluntad (en el sentido que Schopenhauer daba a este término). Pero la determinación que lleva a cabo la buddhi es una determinación intelectual, vinculada más al proceso de nombrar, ordenar y distinguir, que a los mecanismos del deseo. A la buddhi se le atribuye virtud, discernimiento, desapego y, sobre todo, poder. De ella emana el sentido de la identidad (ahamkāra), del que surgen los once órganos de la sensibilidad y los cinco elementos sutiles, que darán forma a los elementos físicos.

En el estadio evolutivo anterior no había todavía una diferenciación entre la acción de determinar y el agente que determina. Ahora se observan los resultados. El principio intelectivo deriva en reflexión, presuponiendo un «yo». De este modo surge el sentido de la identidad (ahamkāra) ${ }^{18}$. El yo encuentra, tanto en sí como fuera de sí, cierta potencia y cierta resistencia. La dualidad de lo individual es precisamente la que permite concebirlo no como una entidad separada de las demás, sino como una "personalidad» que no se encuentra propia y exclusivamente en ella misma, sino que es consecuencia natural del principio intelectivo. Lo cósmico se ha hecho personal. De ahí que se considere al yo como un vehículo que asimila el pensamiento de otro (en este caso de la buddhi, donde se refleja la conciencia del purușa) y su presumida acción (del yo), es en sí teatro y no fuente. Dado que no existe una diferencia esencial entre causa y efecto (estados latentes o manifiestos), tampoco la habrá entre el sujeto y la acción que realiza. Esta es quizá la idea más original del sāṃkhya: la inspiración (la fuente) es el

18 SK 22-25. (Larson, 1987, 262-264). TK 89-137. (Jhā, 1896, 61-66). 
purusa, que se encuentra fuera del espacio y del tiempo, y el individuo su teatro. El individuo como escenario de un drama cósmico.

De ambos, del intelecto y del sentido de la identidad (buddhi y ahamkāra), surgirá la mente (manas), con capacidad para la acción y para la sensación. Naciendo así lo subjetivo. ¿Cómo se explica este proceso? El principio de individuación (ahamkāra) se desdobla en lo psicológico y lo inerte (ambas son evoluciones rigurosamente materiales). Al primero pertenece la capacidad de explicar y formar conceptos (samkalpa ${ }^{19}$ ), el pensamiento reflexivo (manas), las facultades sensibles (buddhIndriya) y la capacidad de actuar (karmendriya). De ambas capacidades surgen los elementos sutiles (tanmātra). La función hace al órgano y estos elementos sutiles, en su faceta tamásica, crean los elementos toscos (mahabhütas) que constituyen el mundo físico.

Desde una perspectiva objetiva, el sāṃkhya define la transformación continua de la materia como un proceso tripartito, cuya actividad se atribuye a rajas, su ordenación a sattva y su objetivación a tamas. Desde una perspectiva subjetiva, estas tres funciones se traducen en diversos estados emocionales: inquietud (rajas), discernimiento (sattva) o confusión (tamas). Toda la actividad del mundo, ya sea físico o psíquico, se mueve siguiendo estos parámetros: la inquietud busca permanentemente la satisfacción, el discernimiento la contemplación, la confusión la estabilidad. Aunque el discernimiento encuentre ocasionalmente estados de dicha, la búsqueda de satisfacción tiende inevitablemente hacia la frustración y la incertidumbre. El entendimiento cabal de dicha situación (según esta taxonomía) constituye el remedio para superar dichos estados de abatimiento.

Nos encontramos ante un peculiar materialismo. La mente y sus intenciones, el pensamiento y sus ideas, las sensaciones, las esperanzas y los temores, el placer y la contemplación, el discernimiento y la reflexión, asociados a sattva y buddhi, no se diferencian esencialmente de otros estados opacos y tortuosos, asociados a tamas y moha, e incluso, aunque se encuentren en peldaños inferiores del proceso evolutivo, no se diferencian de lo inerte e inactivo, de lo ineficaz o de lo que carece de capacidad de reacción (tanmātra, bhüta). De modo que la distinción convencional entre lo subjetivo y lo objetivo obedece a diferencias evolutivas y no esenciales o de raíz. Ambas son consecuencia natural de la combinación trigúnica. Tanto los productos más refinados del intelecto como las vetas más duras del mineral, tienen su origen en dicha materia primordial. La conciencia

19 SK 27. (Larson, 1987, 264). 
de existir, el recuerdo o la evocación, la imaginación o el deseo son, desde esta perspectiva, procesos estrictamente materiales. Pasado, presente y futuro resultan de la actividad trigúnica. Todo lo que existe, todo lo que existió y existirá, desde el gran Brahmā hasta la más insignificante brizna de hierba, es resultado de dicha interacción ${ }^{20}$.

\section{La mente}

Detengámonos ahora en uno de los órganos de los sentidos más singulares, el principio reflexivo: la mente (manas), sede y centro de operaciones de todos los restantes. Las impresiones de los sentidos se definen en el sāṃkhya como el efecto inmediato del sentido de la identidad. La mente es la única facultad que toma parte de los sentidos objetivos y subjetivos, es decir, en la percepción cognitiva (buddhindriya) y en la facultad de actuar (karmendriya), sino fuera así, la acción no sería posible. Esto no quiere decir que los sentidos no actúen, lo hacen, pero su actividad sólo es reconocida mediante la intervención de la mente, que es donde se asocian los dos ámbitos y se generan las intenciones.

La mente es reflexiva en tanto que suministra formas y cualificaciones a la percepción directa de las cosas, distinguiendo lo semejante de lo diferente, atribuyendo propiedades e identificando objetos ${ }^{21}$. Al ser producto de la materia primordial, tiene una naturaleza gúnica y su función cognitiva consiste en adquirir la forma de los objetos que conoce mediante la transformación de su propia constitución interna. Se trata de una sustancia altamente maleable, capaz de adoptar formas muy diversas en función del recorrido de su experiencia. Esa flexibilidad no implica en modo alguno que la mente contribuya a crear el mundo, aunque sí al modo de experimentarlo. Se plantea entonces la cuestión de si la mente debe considerarse uno de los sentidos. Se responde afirmativamente, dado que tiene propiedades similares a estos. Respecto a cómo una entidad tan multifacética puede derivarse de un único principio (ahạ̣kāra), se contesta (sin entrar en detalles) que debido a las modificaciones específicas de los gun $a^{22}$. Sea como fuere, se postula la continuidad entre lo inteligible y lo sensible.

\footnotetext{
20 SK 54. (Larson, 1987, 272)

21 TK 155. (Jhā, 1896, 67)

${ }^{22}$ TK 157. (Jhā, 1896, 68)
} 
Los tres órganos internos: el principio intelectivo, el sentido de la identidad y la mente (buddhi, ahamkāra y manas) se diferencian por las diversas funciones que desempeñan. El principio intelectivo se caracteriza, como dijimos, por la determinación (adyavasāya). El sentido de la identidad se caracteriza por la autoafirmación del ente (abhimāna). Y la mente se caracteriza por la reflexión o deliberación (samkalpa ${ }^{23}$. Además de esta función cosmogónica, los órganos internos crean las condiciones que hacen posible la vida de los organismos psicofísicos, llevando a cabo una función común: el mantenimiento de la vida mediante la circulación del aire vital (prāna). Ya en la Chandogya Upaniṣad se mencionaba el mukhya prāna como el principio sutil de la vida y el elemento regulador del metabolismo, que sirve de enlace entre lo anímico y lo corporal y, en ocasiones, se identificaba con el principio original (brahman $)^{24}$. Vācaspati Miśra especifica los diferentes tipos de aire vital que recorren los conductos energéticos del cuerpo. El aire vital de la respiración, que mantiene la vida del conjunto (reside en la punta de la nariz, el corazón, el ombligo y los dedos gordos de los pies) se denomina präna. El aire descendente, que realiza las funciones de evacuación se denomina apāna y reside en la espalda. El aire que se ocupa de la digestión es el samāna, el aire ascendente udāna (en la garganta), asociado con la exhalación, y vyāna el aire difuso que circula por todo el cuerpo y reside en la piel $^{25}$. Todas estas especificaciones serán incorporadas a las tradiciones médicas del ayurveda.

\section{Dualidad en la cosmología sāṃkhya}

Dentro del dualismo particular que presenta la cosmología sāṃkhya, se produce un nuevo desdoblamiento a partir del sentido de la identidad (ahamkāara): un mundo mental y un mundo físico, un mundo interno, que podríamos llamar psicológico, y otro externo, aunque estrictamente los dos sean evoluciones de la materia primordial y carezcan de actividad consciente propia. El primero lo componen el grupo de once (la mente, los sentidos y las capacidades), mientras que el segundo se encuentra constituido por los cinco grandes elementos (mahābhüta) o elementos físicos. Ambos son consecuencia de la actividad de rajas. La diferencia fundamental entre ellos es que el primero, el grupo de once, participa en alto grado del guna sattva, siendo por tanto luminoso e iluminador

\footnotetext{
23 TK 160. (Jhā, 1896, 70)

${ }^{24}$ CU 1.8.4. (Olivelle, 1998, 178-179)

${ }_{25} T K$ 161. (Jhā, 1896, 70)
} 
(aunque su luz sea prestada). El segundo, sin embargo, es consecuencia del sentido de la identidad cuando es afectado principalmente por el guna tamas ${ }^{26}$. La actividad y transformaciones a que dan lugar estos mundos internos y externos no serían posibles sin el impulso de una fuerza motriz, representada por el guna rajas, dado que sattva y tamas son, cada uno a su manera, inactivos, ineficaces y sin capacidad para la acción.

Así, las facultades (indriya) se definen como el efecto inmediato del sentido de la identidad y se encuentran constituidas principalmente por la luminosidad reflejada del sattva. Estas se dividen en dos tipos: aquellas asociadas a la percepción (buddhindriya) y aquellas asociadas a la acción (karmendriya) ${ }^{27}$. Entre estas facultades hay que incluir la mente (manas), la más sofisticada de todas ellas y el centro de operaciones tanto de la percepción como de la acción. La mente se define como facultad deliberativa (samkalpaka) y principio reflexivo ${ }^{28}$. Es reflexiva en tanto que suministra formas y cualificaciones a la percepción directa de un objeto, es deliberativa en tanto que distingue lo semejante de lo diferente, atribuye propiedades e identifica ${ }^{29}$.

Respecto a la percepción, que se sirve de los tres órganos internos, puede ser instantánea o gradual ${ }^{30}$. Mientras que respecto a lo invisible es necesario inferir a partir de lo percibido o a partir de lo escuchado en testimonios dignos de confianza. En este último caso los órganos internos operan sin la ayuda de los externos, pero se sirven de uno de los tres medios válidos de conocimiento reconocidos por el sāṃkhya, el testimonio verbal.

Ya hemos visto que la primera manifestación de la materia primordial es fundamentalmente sáttvica y que de dicho fundamento (buddhi) emerge el resto del cosmos. Decir que el primer producto que destila el universo es la inteligencia es decir ya mucho. Esa primera luz comprende la inteligencia de todo organismo individual, de lo que es y de lo que proyecta ser, además de los elementos físicos (bhüta) resultado de la evolución cósmica. No estamos hablando únicamente de la inteligencia de los cuerpos: la respiración, la percepción o la destreza, sino también de la inteligencia de los elementos: la inteligencia del agua, el fuego o el espacio.

\footnotetext{
26 SK 25, TK 151-152. (Jhā, 1896, 65-66)

27 SK 26, TK 153. (Jhā, 1896, 66)

28 SK 27, TK 154. (Jhā, 1896, 67)

29 TK 155. (Jhā, 1896, 67)

30 SK 30, TK 162-3. (Jhā, 1986, 71)
} 
Este primer estadio de la evolución es denominado buddhitattva, que crea gradualmente un sentido de autoafirmación (ahaṃkāra). A partir de aquí ocurre una bifurcación, dando paso a dos corrientes evolutivas, una sáttvica y otra tamásica, en cada una de las cuales se forma un sentido del yo o de la propia identidad. El guna rajas sirve en ambas de elemento dinamizador de las transformaciones. La primera corriente desarrollará las capacidades cognitivas del organismo (la mente y los sentidos), así como sus capacidades de acción. La segunda corriente producirá, gracias a carácter sáttvico de la buddhi, formas aladas, los llamados elementos sutiles (tanmātra) ${ }^{31}$, y mediante sus componentes tamásicos, formas pesadas, los elementos físicos (mahäbhüta), que se caracterizan por su homogeneidad, inercia y solidez ${ }^{32}$.

Del sentido de la identidad (ahamkāra) surgen los elementos sutiles (tanmätra), cuya naturaleza es percepción. Estos tienen capacidad generativa y crean los grandes elementos (mahäbhuta) o lo que podríamos llamar elementos físicos. ¿Cómo se realiza esta operación? Del primer elemento sutil, el sonido, surge el espacio (ākáśa), que tiene como característica primordial lo sonoro (śabda), entendido implícitamente como una vibración del espacio. De la combinación del sonido con el segundo elemento sutil, lo táctil (sparśa), surge el aire o viento (vāyu), que tiene como características fundamentales lo táctil y lo sonoro. Del mismo modo, de la fusión de lo sonoro, lo táctil y lo visual (rüpa), procede el elemento fuego (tejas), asociado a lo luminoso. Si a estos tres le añadimos el gusto (rasa), surge el elemento líquido, el agua (jala). Finalmente, de la combinación de los cuatro elementos sutiles con el olfato (gandha), surge el elemento tierra (prthivi $)^{33}$.

La palabra sánscrita bhüta designa lo que ha ocurrido, lo formado y creado, lo pretérito y anterior (de ahí que la mitología lo asocie con fantasmas y espectros). Los cinco grandes elementos o elementos físicos, tierra, agua, fuego, aire y espacio, son bhüta precisamente por ser una formación o sedimento de los elementos sutiles. De nuevo el énfasis generativo se localiza en la percepción, algo muy común en la filosofía india. Lo perceptivo crea el ámbito donde desarrollarse. La función hace al órgano. El espacio se considera evolución del sonido, el aire consecuencia del tacto, el fuego de la forma, el agua del gusto y la tierra del olfato.

31 SK 28. (Larson, 1987, 267). TK 184-186. (Jhā, 1896, 79-80).

32 SK 22 y 25. (Larson, 1987, 262-3). TK 141-143 y 151-152. (Jhā, 1896, 61-62 y 65-66).

33 TK 143. (Jhā, 1896, 67). 
Lo contingente y lo limitado, lo que se da en el mundo natural, se define aquí como «ser para otro», y se representa mediante el principio femenino. Como hemos visto, el mundo natural, emanado de la materia primordial (prakrti), tiene como elementos constitutivos los tres guna, que en última instancia consisten en sensaciones de dicha (sattva), inquietud (rajas) o confusión (tamas). Todo lo originado a partir de la buddhi (el principio intelectivo) tiene esa condición "transitiva», del mismo modo que los objetos, una silla o un vestido, tienen todos su función, «son para» (sentarse, abrigarse). De nuevo la inferencia tiene aquí una naturaleza típicamente experiencial (más que experimental), muy característica del sāṃkhya. Estamos acostumbrados a explicar la percepción partiendo de los elementos físicos o materiales (el órgano sensible, el fotón, la neurona, etc.), pero aquí es la materia la que se explica mediante lo que se experimenta, mediante lo que se percibe o siente: dicha, inquietud y confusión.

Esta matización es importante en el conjunto del sistema, pues el razonamiento para justificar la existencia del purușa se basa en dicha condición experiencial del conocimiento. Desde esta perspectiva, la experiencia se estructura mediante sensaciones (sattva, rajas y tamas) en continua fluctuación e interacción. Explicar dicho proceso de transformación en función de otros estados cuya naturaleza sería también trigúnica, nos llevaría a una regresión infinita ${ }^{34}$. Se hace necesario postular un fundamento estable a todo ese cambio, inferir el reverso del mundo natural (el reverso de todas nuestras experiencias sensibles y reflexivas). Siendo el mundo natural discreto, subjetivo, inquieto; dicho reverso deberá ser completo, objetivo, sereno, y eso es el purușa. Un fin en sí mismo y no un «ser para otro", como es lo natural.

Siguiendo este razonamiento, se infiere la existencia de un espíritu, al margen de la materia, que constituya la sede de las experiencias, ya que la materia se considera ciega, algo así como un puro mecanismo inconsciente. Cualquiera experimenta cotidianamente sensaciones agradables o desagradables, placenteras o dolorosas. ¿En quién se producen? No en el sujeto empírico, contesta Vācaspati Miśra, que está hecho de esas mismas sensaciones, sino a una entidad más allá de la propia sensación: el purusa. Como se ha mencionado, si las sensaciones fueran agradables o desagradables para la intelección (buddhi) y sus derivados, ello implicaría un argumento circular: la sensación no puede ser sujeto de la sensación, dado que la intelección misma se encuentra constituida por ellas ${ }^{35}$.

$34 T K$ 121. (Jhā, 1896, 53).

35 TK 123. (Jhā, 1986, 55) 


\section{Conclusiones}

La filosofía sāṃkhya es antigua y, según dicen todos los manuales, dualista. Pero la palabra «dualismo» es reciente. Ni siquiera los maniqueos la utilizaban. El término apareció en Europa a caballo entre los siglos XVII y XVIII, de la mano de Hyde, Leibniz y Bayle. Posteriormente Christian Wolff le daría un significado filosófico. Para Wolff dualistas eran aquellos que admitían la existencia de sustancias materiales e inmateriales, concediendo a los cuerpos existencia real fuera de las almas y considerando a las propias almas inmateriales. Si rastreamos los diversos dualismos a lo largo de la historia, encontramos que la mayoría de ellos afirman la existencia de dos substancias o ámbitos esencialmente diferentes. El más célebre es quizá el de Platón: mundo sensible y mundo inteligible, que ejercerá una marcada influencia en los dualismos gnósticos y maniqueos. La pregunta se repetirá a lo largo de la historia del pensamiento. Se trata de averiguar si el universo se encuentra regido por un único principio o es el espacio de confrontación (o convivencia) de dos principios irreductibles. Tras el Renacimiento, de tendencia monista, el dualismo revive en la edad moderna con Descartes y su concepción de las relaciones mente/cuerpo: res cogitans y res extensa, de amplia resonancia en el pensamiento contemporáneo. No obstante, el trato entre los dos principios puede ser muy variado. De manera general el catálogo de relaciones puede organizarse en tres categorías: hostilidad, colaboración y complementariedad ${ }^{36}$.

Más preocupada por cuestiones epistemológicas, la edad moderna ha convertido la vieja querella entre realistas e idealistas en una oposición entre dualistas e idealistas. Para Kant, cuando alguien empieza a dudar de la realidad de los objetos externos a la mente, se está convirtiendo, lo quiera o no, en idealista. Mientras que aquel que no duda se convierte inmediatamente en dualista, separando los objetos del sujeto pensante y concibiéndolos al margen de su propia experiencia. Según esta postura, la materia ya no es un fenómeno de la conciencia, es decir, una mera representación del espíritu a la cual le corresponde un objeto desconocido, sino que se postula una cosa en sí al margen de toda sensibilidad.

Para el sāṃkhya, a diferencia de las concepciones cosmológicas modernas, la inteligencia madruga en el universo. No es el resultado final de una larga

36 Obsérvese la ausencia de la idea de jerarquía, que podría transformar el dualismo en monismo, como sostendrían algunos neoplatónicos. El dualismo requiere que las substancias o principios sean insubordinables. 
evolución de lo simple (el átomo de hidrógeno) a lo complejo (la materia orgánica), sino el fundamento mismo de dicha transformación. La inteligencia primordial (buddhi) es anterior a la capacidad de los entes de asumir o «hacer suyo" su discurrir evolutivo. Hay inteligencia previa a la constitución de las diversas identidades, que posteriormente, participaran de ella. Esa inteligencia es, además, extremadamente sutil. Aquí el sāṃkhya se acerca a las cosmologías evolutivas modernas. Lo sutil (la radiación) se sitúa en el origen, y su evolución da paso a la materia tosca (los elementos pesados, esenciales para la constitución de la materia orgánica y sintetizados en los hornos estelares). Es así como se realiza la transición de los tanmātra a los mahābhüta. Y es la aspereza de estos cinco grandes elementos la que constituye lo que nosotros llamamos realidad física, siendo la empírica o experiencial aquella de la que participan los órganos internos. En este punto la distancia vuelve a crecer si consideramos que, en el sāṃkhya, los órganos internos incluyen la inteligencia primordial, una inteligencia inmanente que organiza los diferentes niveles del material cósmico.

\section{Bibliografía}

Dasgupta, Surendranath. A History of Indian Philosophy. Delhi: Motilal Banarsidass; 1992 (1ª edición: Cambridge 1922).

Filliozat, Jean. La doctrine classique de la médicine indienne, Ses origines et ses parallèles grecs. Paris: Imprimerie Nationale; 1949.

Frauwallner, Erich. History of Indian Philosophy. Delhi: Motilal Banarsidass; 1973.

Garbe, Richard. Die Säṃkhyya Philosophie. Leipzig: H. Haessel; 1917.

JHĀ, Gangānātha. The Saṃhya-Tattva-Kaumudi: Vacaspati Misra's Commentary on the Samkhya-karika. Delhi: Chaukhamba Sanskrit Pratishthan; 2004. (1a edición, Bombay 1896).

Larson, Gerald. Classical Sämkhya. An Interpretation of its History and Meaning. Delhi: Motilal Banarsidass; 1987.

Larson, Gerald, y Bhattacharya, Ram. Encyclopedia of Indian philosophies (v.4), Sämkhya. A Dualist Tradition in Indian Philosophy. Delhi: Motilal Banarsidass; 1987.

Olivelle, Patrick. The Early Upanisads. Annotated Text and Translation. New York: Oxford University Press; 1998.

- The Law Code of Manu. New York: OUP; 2004.

- Life of the Buddha by Ashvagosha. New York: New York University Press; 2008. 
Pujol, Óscar, y Domínguez, Atilano. Patañjali / Spinoza. Valencia: Pre-Textos; 2009.

Rangarajan, L.N. (ed/trad). Kautilya: The Arthashastra. London: Penguin Classics; 1992.

Sharma, Ramkaran, y Bhagwan Dash, Vaidya. Caraka Sambita. Text in Sanskrit with English translation. Varanasi: Chowkhamba Sanskrit Office; 2009.

Recibido: $26 / 06 / 2013$

Aceptado: 26/09/2013 
